\title{
Not so deep inconsistency: a reply to Eklund
}

\author{
JC BEALL \\ PHILOSOPHY DEPARTMENT, \\ THE UNIVERSITY OF CONNECTICUT \\ jc.beall@uconn.edu \\ Graham Priest \\ SCHOOL OF PHILOSOPHY, \\ THE UNIVERSITY OF MELBOURNE \\ g.priest@unimelb.edu.au
}

Received by Greg Restall

Published November II, 2007

http://www.philosophy.unimelb.edu.au/ajl/2007

(C) 2007 JC Beall and Graham Priest

\section{INTRODUCTION：DEEP INCONSISTENCY}

In his 'Deep Inconsistency' (2002a), Eklund attacks arguments to the effect that some contradictions are true, and especially those based on the liar paradox, to be found in Priest (1987)-hereafter, IC. The point of this paper is to evaluate his case 1

Eklund's argument turns on the distinction between being analytic and being meaning-constitutive (мС). He explains the distinction as follows (p. 322):

... we should distinguish between the property of being meaningconstitutive in the sense of being true by virtue of meaning and the property of being meaning-constitutive in the sense that anyone fully competent with the expressions employed, in virtue of her competence, is disposed to accept them ... Let us call principles ... [of the first kind] analytic, and reserve the label meaning-constitutive for meaning constitutivity in the second sense.

Eklund contends that the principles that give rise to the liar paradox and similar paradoxes of self-reference are $\mathrm{MC}$, but not true, and a fortiori, not true

${ }^{\mathrm{I}}$ In what follows, page references are to his article, unless otherwise indicated. We are grateful to Eklund for comments on an earlier version of this paper. 
in virtue of meaning, not analytic. In other words, we may suppose that the principles concerning truth that are MC are inconsistent but not true ${ }^{2}$ If this is the case, arguments based on these principles collapse.

What are we to say about notions, such as truth, for which the MC principles are inconsistent? In such cases (p. 322):

the semantic values of the expressions ... [concerning the notion] are what come closest to making the meaning-constitutive principles true.

The result will be consistent, according to Eklund, since no contradictions are true. But the maximisation is not egalitarian: More weight should be given to the holding of those principles that are more 'firmly entrenched', or 'more fundamental' (ibid.). (For that reason, it might be better called 'optimisation' than 'maximistation'.)

So much for an outline of Eklund's position. Now for some of its problems.

\section{EKLUND'S DISTINCTION}

First, there are problems generated by Eklund's distinction between analyticity and meaning constitutivity. In Section 5 of his paper, Eklund points out that the distinction cannot be maintained against what he calls a responsedependent account of meaning, in which the truth of certain sentences just is constituted by our dispositions to accept them. The distinction is defended at greater length by Eklund in his (2002b), where, however, he himself notes that it does not make sense against standard truth-conditional, conceptual role, or Fregean semantics-at least when the semantic dispositions of speakers are inconsistent. These accounts have to be modified, crucially, to allow for the semantic dispositions to be fallible.

Let us consider these fallible dispositions. Call a disposition constitutive of semantic competence an sc-disposition. The crucial question concerns what accounts for these. Is it the case that:

I. a speaker posses sC-dispositions in virtue of a prior grasp of the facts of meaning?

Or is it the case that:

2. a speaker's possession of sC-dispositions is simply a brute fact of semantic competence?

On the first answer, the fallibility of the dispositions seems to give rise to absurdity. Let us illustrate with respect to truth and the T-schema, though the

${ }^{2}$ Eklund calls this 'deep inconsistency', but in the context, this is not a terribly appropriate nomenclature since the given 'inconsistency' is of only a relatively superficial kind. 
point is quite general. The facts of meaning determine that some T-instances, but only some, are analytic; the rest are false. Why, then, is it that a disposition to accept all of them is constitutive of a grasp of meaning? Consider a speaker who is disposed to accept the analytically true ones but not false ones. On Eklund's account, this is an incompetent speaker: they do not understand the meaning of 'true'! This is surely absurd. It is the speaker who is disposed to endorse all of them whose grasp of meaning is less than perfect.

Eklund, we take it, does not accept I, and wisely so, for the reason given. But let us now turn to 2. According to this, a speaker does not have sCdispositions because of an independent grasp of meanings or, for that matter, any special grasp of meaning at all. The sc-dispositions are simply brute facts of semantic competence. But if we cannot appeal to an independent grasp of meanings, we have a clear problem: How are sc-dispositions to be distinguished from dispositions that hold in virtue of mere belief. People, after all, are disposed to accept many claims that would seem to have little to do with semantic competence. Consider the disposition to accept that the world is older than I minute. All competent speakers of the language-barring some malfunction that hinders competency-have that disposition. Why is that not an SCdisposition? There would seem to be no principled reason for claiming that it is not 3

There is no hope of drawing the distinction epistemologically. Most of the dispositions that people have to accept things they have in virtue of being told. But this is equally true of contingent claims, such as that Canberra is the capital of Australia, and analytic claims, such as that one is a number. Nor is there any hope of drawing the requisite distinction simply in terms of behavioural dispositions. The person who is inclined to accept that witches have intercourse with the devil because this is true by definition and the person who thinks that this is a true empirical fact is hard to discern. This, of course, is one of the lessons of Quine's celebrated 'Two Dogmas of Empiricism' 4

Worse is in store for those who would subscribe to a theory of meaning of the kind in question-to the effect that meanings supervene on our behavioural dipositions. It would appear to be an essential fact about meaning that it is compositional. The meaning of a whole must be a function of the meanings of the parts. But if the facts of meaning are determined by defeasible dispositions of speakers, there is absolutely no reason to suppose this to be so. Not even the truth value of a sentence is determined by the truth values of its parts. Thus, speakers may be disposed to accept that Sherlock Holmes

\footnotetext{
${ }^{3}$ Furthermore, if there's no principled way to distinguish sc-dispositions from other dispositions, then, since all people have different dispositions to assert, it follows that all people speak different languages.

${ }^{4}$ One might suggest that a disposition is MC just if we take it to be such. This will not work either. It implies that speakers have an infallibility about meanings that they do not have. Someone, for example, who takes the disposition to accept that pigs can fly to be MC (of 'pigs') is just plain wrong.
} 
was either right handed or left handed, without being disposed to accept either that he was right handed or that he was left handed. There is therefore little hope of explaining the compositionality of meaning.

In the present context, matters are even worse. Eklund requires not just a behaviouristic account of meaning, but one that permits an optimisation procedure of the kind he has in mind. But the account queers the pitch for many reasons. First, there is the problem of distinguishing between those things that speakers are disposed to accept in virtue of semantic competence and those that they are disposed to accept in virtue of mere belief. Next, however one draws this distinction, it is almost certain that the relevant distinctions will vary from person to person. Finally, on any reasonable behavioural criteria, what a person accepts is likely to be a vague matter. How the optimisation process is supposed to work in these contexts is, at the very least, a pressing question for Eklund.

We do not rule out the possibility that the difficulties that we have been pointing to can be given satisfactory answers, but the considerations show, at least, that a lot more work needs to be done before Eklund's crucial distinction can fly.

As it turns out, though, this is all just softening up. For the major problems of Eklund's attack on dialetheism have nothing to do with his views about meaning. For the sake of argument, let us grant for the rest of this paper that they can be worked out in a satisfactory fashion.

\section{THE IGNORATIO}

The major problem with Eklund's paper is that it appears to rest on a simple ignoratio. Eklund says (p. 323):

Priest's argument is in effect rather simple. He defends each principle made use of in the liar reasoning on the ground that the meanings of the expression employed require that the principle be true...

But that is just wrong.

It is true that in the introduction to IC (Chapter o) it is claimed that the T-schema and similar principles involved in the paradoxes of self-reference are analytic. But analyticity is not necessary for the argument to true contradictions: simple truth will do. And once the detailed arguments concerning the liar paradox and its like are commenced in $I C$, analyticity plays no role at all. (The term does not even occur in the index of the book!) Thus, in Chapter I, a set of conditions that entail contradiction (the Tarski conditions) is specified and defended. These do not mention analyticity; and it is simply their truth that is defended. 
That it is truth, not analyticity, that is important is flagged, in fact, even in the introduction to $I C$, where it says that principles such as the T-schema (IC, p. 5):

are a priori and, one might argue, analytic, specifying as they do (at least in part) the defining conditions of the notions concerned. At any rate, they are true. Now the point is that such principles, possibly on their own, possibly with the connivance of other contingent truths donated by the world, entail statements of the form: $\alpha$ and not- $\alpha$, which must therefore be true, entailment preserving truth ...

Discussions of analyticity are, therefore, beside the point 5

It should also be noted that the case for dialetheism in IC employs a number of arguments that have nothing to do with the paradoxes of self-reference; for example, the arguments concerning change and motion in Chapters 9 and Io, and the legal and normative arguments of Chapter II. Eklund claims that his considerations apply to all of these (p. 326). But that is just false. For example, in the legal case, it is not even plausible to suppose that the statements that give rise to contradiction (e.g., that persons of a certain kind have the right to do such and such —or that a duly constituted legislature has passed a law to this effect) are analytic.

\section{TRUTH}

As we have just observed, it is only the truth of the T-schema and similar principles that is at issue, not its analyticity. There are many arguments for this that have nothing to do with analyticity. For example, deflationists about truth hold that the T-schema constitutes everything there is to be said about truth. Some, it is true, have been tempted by the thought that one can get away with making exceptions; but within the context of deflationism the idea seems entirely unmotivated ${ }^{6}$

Even if one is not a deflationist, there are reasons for accepting the truth of the instances of the T-schema. One is the fact that we use truth as a disquotational device to endorse what others say, even though we do not know exactly what they say, or to endorse an infinite number of things in a finite

\footnotetext{
${ }^{5}$ Note that, strictly speaking, even the T-schema itself-though we (the authors) endorse itmay not be necessary for the Liar-related arguments for dialetheism to go through. Even in the conditional-free fragment of a language (and, hence, the T-schema-free fragment), 'true' might work in such a way that the inferences from $T\langle A\rangle$ to $A$ (and back) are valid. In that fragment, we have no T-schema (as the fragment is conditional-free) but may well have Liar-like sentences that, given valid rules in the fragment, none the less result in true contradictions. So, not only is analyticity not required, but even the T-schema itself is not strictly required. That said, our chief response to Eklund's ignoratio remains as above: only the truth, not the analyticity, of the $\mathrm{T}$-schema is required.

${ }^{6}$ See, e.g., Priest (2000), Beall and Armour-Garb (2003).
} 
way. Thus, we say The last words uttered by Newton are true, or Every sentence of the form 'Hegel believed that A' is true. If truth did not satisfy the T-schema such acts would misfire 7 Eklund says nothing about such arguments. He does not even say what his own account of truth is. In fact, he does not seem to think this a particularly important issue. He tells us that given his view (p. 323):

the actual semantic values of the truth predicate and the logical expressions can in principle be exactly what they are on more standard accounts of the liar; say Kripke's (just to take an example).

This is exactly not the case. All standard accounts of truth, including Kripke's, run into problems of well known kinds (which, again, have nothing whatsoever to do with analyticity, and so to which Eklund's distinction is irrelevant). All are subject, for example, to strengthened versions of the liar paradox. Thus, if one takes it that the liar sentence is neither true nor false (as does Kripke), then one has only to consider the sentence 'This sentence is not true'. If it is neither true nor false, it is not true, and so true. Moreover, there are reasons as to why problems of this kind would seem to be inevitable. Such things are well known and there is no need to dwell on them here ${ }^{8}$ We note them only to point out that what is needed to solve the liar paradox is an account of truth, not of the meaning-theoretic status of its principles. Since Eklund does not engage with this issue, there is, in a sense, nothing in his paper to answer.

It may be that the reason Eklund seems not to be too bothered about the details of a theory of truth is that he takes it that the optimisation process that determines what it is will ensure that it is consistent. Whether or not this is so we will come to in a moment. Note, though, that even if this is the case, it provides no reason to ignore the issue. Standard problems concerning consistent accounts of truth (such as extended paradoxes) arise precisely because truth is taken to be consistent. Recall Tarski's Theorem.

Finally, it should be noted, Eklund's failure to spell out an account of truth, besides leaving him 'out of the game' (as it were), makes his own thesis problematic. Eklund's chief claim-namely, that not all instances of the T-schema are true-itself employs 'true'. The consequences of that claim-what follows from his chief claim - therefore turns on the theory of truth behind it. The various standard theories differ, of course, with respect to what follows from 'true'-ful claims (claims that use 'true'). But, then, such standard theories may well differ with respect to the consequences of Eklund's chief claim. In that respect, his failure to specify a particular theory of truth leaves Eklund's chief claim undefined.

${ }^{7}$ Of course, one might object that for such un-mentioning we need only the left-right-direction of the T-schema. That's true, but to make rationally warranted claims, one needs both directions. After all, what, if not the right-left-direction (rld), is one's warrant for asserting $T\langle A\rangle$ ? The warrant comes precisely from two sources: one's warrant for A itself and the rld of the T-schema (or, perhaps, some valid rule that, in effect, amounts to the rld of the T-schema).

${ }^{8}$ See, for example, Priest (1987), ch. I and Priest (1995), esp. part 3. 


\section{OPTIMISATION}

Let us now turn to Eklund's claim that truth, whatever it turns out to be, is consistent. As we noted in \$??, he argues that a correct account of truth is the one that comes closest to making the MC principles true, that is, one that maximally preserves the (relevantly weighted) MC principles about the notion. (There is, of course, no reason to suppose that such a theory is unique.) If one assumes that the truth is consistent the result follows. But in this context, one cannot simply assume that truth is consistent. As Eklund himself notes (p. 323), the Law of Non-Contradiction (LNC) is but one principle (schema) that is part of the data to be maximised. It may therefore fall in the optimisation procedure 9

Eklund summarily dismisses the possibility that the result of the maximisation may be inconsistent, on the ground that the LNC is so well entrenched and fundamental, and its weight in the optimisation procedure therefore so high, that it is unlikely not be respected in the procedure. Thus (p. 33I):

Although it is possible that the correctness of our ... [MC dispositions] is best maximised if true contradictions are allowed ... provided we abhor contradictions in the way earlier discussed, it is ..., I would argue, not likely.

Unfortunately, what argument Eklund would give, we are left guessing. Optimisation, by its nature, depends on the inter-relation of many factors. It is not determined by any one of them.

Why might one suppose that the LNC is likely to be preserved in the optimisation process? Eklund waves at entrenchment. The question, then, is this: What does it mean to say that the Law is entrenched? The entrenchment of the Law could mean that it is very strongly believed (by many people). This may be true $\sqrt{10}$ But it can hardly be maintained that high weight should be given to the Law simply for that reason. Consider the insane man who believes, very strongly but groundlessly, that he is a saucepan: maybe he is also disposed to believe that he is not saucepan-shaped (because he can see this). In a consistent optimisation of his beliefs, one would hardly want to weight the belief that he is a saucepan higher simply because it is the stronger belief.

\footnotetext{
${ }^{9}$ Actually, it is not obvious that the LNC is even a candidate for being preserved in the optimisation process. That many people have a disposition to assert the LNC may be obvious, but recall that what is to be maximised are those sentences that speakers have a disposition to accept in virtue of their linguistic competence. And it might be suggested that the dispositions concerning the LNC are not part of this competence at all—simply the result of some process of education (or indoctrination).

${ }^{10}$ Though one may certainly contest this. Arguably, what most people believe is a restricted version of the LNC, a principle (schema) defined only over the T-free fragment-or, at best, only over the 'grounded' fragment. It is difficult to accept that most people would readily accept the LNC if, contrary to fact, they (most people) were fully aware of Liar-like sentences. (It's very easy to accept the LNC if one's stock of potential counterexamples ignores the semantic paradoxes!)
} 
Presumably, then, it is not simply the strength of the belief that is important, but the rationality of the belief. Now, is belief in the LNC so rational? Well, many people assume so; but assuming so does not make it so. And when we review the reasons for the Law, they are (to put it mildly) disappointing. The only sustained defence of the law that there has ever been is Aristotle's in book Gamma of the Metaphysics. And this is terrible ${ }^{m}$ Reasons of a nonquestion-begging kind seem hard to come by. The honest view is that the Law is not rationally grounded ${ }^{12}$ Eklund, at an rate, does not even attempt to provide a defence of the rationality of the Law.

Another possibility is that entrenchment should be understood as something like centrality to the web of belief, in Quine's sense. How to cash out this idea is not an easy question either. As a first cut, it is something like this: a belief is central if its revision would occasion a drastic modification of the whole web of beliefs. (In one of Quine's pithy dictums, when modifying the web we should adopt a maxim of minimum mutilation.) This is obviously vague, and it is not clear how to explicate the notion of a drastic modification in a satisfactory way. However, the account will suffice for the present. The question now is whether the LNC is central in this sense.

The centrality of the LNC is often asserted (without backing). But is the LNC central? No. The reason is as follows. A paraconsistent logician has ways of simply subsuming any reasoning that is acceptable to a classical logician. We will not go into all the details here ${ }^{13}$ but the basic idea is this. A paraconsistent logician, if reasoning about a consistent situation, can use classical logic (in much the way that an intuitionist logician can use classical logic when reasoning about finite situations). Classical logic is just the special case of paraconsistent logic (at least its extensional part) restricted to consistent situations. Now, the only situations that make sense from a classical perspective are consistent ones. Hence, reasoning about any situation that makes sense from a classical perspective makes sense from a paraconsistent perspective also. It is just that from a paraconsistent perspective there will be other situations about which we can reason, which make no sense from a classical perspective. The effects of rejecting the LNC, then, are not at all as drastic as one might have been supposed. In just the way that the discovery of another country does not affect our beliefs about this country, the discovery of inconsistent situations does not affect our beliefs about consistent situations.

Even if the LNC were entrenched in any of the senses we have been discussing, it would still not be at all obvious that in a process of optimisation it will be retained. Many small factors can, after all, outweigh one big factor. And beliefs that are entrenched are reasonably jettisoned sometimes. The beliefs that the earth is stationary, or that biological species are fixed, would seem to

\footnotetext{
${ }^{\text {II }}$ This claim is backed up in detail in Priest (1998).

${ }^{12}$ Again, this view is backed up in detail in Priest (200I).

${ }^{13}$ They can be found in Priest (1987), ch. 8 .
} 
be just such beliefs.

And there are certainly factors that speak against the Law, many of them not so small[14 Thus, on nearly everyone's view of what counts as a good optimisation, simplicity is a major desideratum. What, exactly, simplicity amounts to is a moot point. But, on pretty much any understanding of the notion, a paraconsistent logic such as LP plus the naive account of truth (that is, one that endorses all the inferences from a sentence to its truth, and vice versa) is simpler than all consistent accounts of truth, based, as they tend to be, on complex ordinal hierarchies, not to mention the further ad boc hypotheses needed to avoid problems about strengthened forms of the liar paradox ${ }^{15}$

Finally, note the following. We have been talking, so far, as though in the optimisation process one has to choose between inconsistency and the LNC. One does not. If one subscribes to a paraconsistent logic one can have every instance of the Law, $\neg(A \wedge \neg A)$, together with sentences of the form $A$ and $\neg A$ (maybe because one also endorses all instances of the T-schema) ${ }^{16}$ Whatever sentence is taken to express the LNC, one can accept that and some contradictions as well. If you really want to maximise dispositions, this is the way to go 17 Of course, there will be some things that cannot then be endorsed. The most obvious of these is the conditional $(A \wedge \neg A) \rightarrow B$ (assuming that the maximisation also endorses modus ponens). But recall that we are supposed to be maximising those sentences which semantic competence requires a disposition to accept. And the conditionals in question are hardly of this kind. Most native speakers are not just disposed not to accept these conditionals: they are disposed to reject them. We do not take this as a mark that the speakers do not understand conditionals. If these considerations are right, then the process that maximises those sentences that we are disposed to accept in virtue of our semantic consequence will not require the rejection of anything. You can have your inconsistent cake and eat it too.

It might be suggested that, just because it is possible to endorse $\neg(A \wedge \neg A)$ and a contradition, this sentence is not really an expression of the Law of NonContradicition at all. The Law cannot be captured by accepting or endorsing any sentence; it is to be captured by rejecting — by rejecting any claim of the

\footnotetext{
${ }^{\text {I4 }}$ This case is argued further in Priest (200I).

${ }^{15}$ While we are on the topic of adhocness, Eklund claims (p. 327) that disendorsing the LNC, as the dialetheists does, is just as ad hoc as many consistency-preserving moves. Well, maybe this depends on what 'ad hoc' means, but the claim is pretty odd. Suppose that you believe in the existence of God, and I provide an argument against it, as a result of which you abandon your view. Your reaction is not, in any standard sense, ad hoc. The same is the case if you disendorse the LNC as a result of the liar argument.

${ }^{16}$ In particular, one may, as some dialetheists (e.g., Beall) do, have the validity of both $\neg(T\langle A\rangle \wedge$ $\neg T\langle A\rangle)$ and $\neg(T\langle A\rangle \wedge T\langle\neg A\rangle)$, and also, for some $A, T\langle A\rangle \wedge \neg T\langle A\rangle \wedge T\langle\neg A\rangle$. This is especially attractive-indeed, dictated-by a 'transparent' (disquotationalist) theory of truth. See Beall (2004, 2005).

${ }^{17}$ Eklund (p. 330) appears to think that you cannot have it both ways.
} 
form $A \wedge \neg A \sqrt{{ }^{18}}$ We agree that such a rejecting is something that has a legitimate claim to be called a version of the Law of Non-Contradiction. We also agree that one cannot respect both a disposition of this kind and a disposition to accept a contradiction. We note only that appealing to the notion of rejection at this point is not a move open to Eklund, since he characterises semantic competence explicitly in terms of acceptance, and acceptance only. Could his framework be modified to incorporate rejection as well? Possibly; possibly not. It is certainly a natural enough thought that semantic competence may involve rejection, though working out the details of an appropriate story is another matter. As for optimisation, even without rejection to worry about, this is a mirky enough notion; when rejection is thrown into the mix, it is not at all clear how it should be supposed to work. Anyway, we are happy to leave this as a problem for Eklund to worry about if he wishes. Even if this is resolved satisfactorily, all our other points remain.

\section{CONCLUSION: NOT SO DEEP CONSISTENCY}

We have now reviewed Eklund's attack on dialetheism. It is based on a distinction about which one might well have one's doubts and, at the very least, about which there are pressing questions. But even given the distinction, the main thrust of Eklund's argument is an ignoratio. The case for dialetheism based on the liar paradox depends upon the truth of the T-schema, not its analyticity. Eklund gives us no theory of truth. In a sense, then, there is nothing in the paper to answer. We can interpret his comments about optimisation as an argument to the effect that the correct account of truth is consistent. But this amounts to little more than an uncritical assumption: it is not seriously argued; and we have seen there are reasons to suppose that optimisation of the kind in question is more likely to result in inconsistency than consistency. In short, Eklund's attack on dialetheism is not a profound one; his view is not so deep consistency.

\section{REFERENCES}

[r] Beall, JC (2004), 'True and False-As If', pp. 197-219 of G. Priest et al. (eds.), The Law of Non-Contradiction Oxford: Oxford University Press.

[2] Beall, JC (2005), 'Transparent Disquotationalism', in JC Beall and B. Armour-Garb (eds.), Deflationism and Paradox, Oxford: Oxford University Press, pp. 7-22.

[3] Beall, JC, and Armour-Garb, Brad (2003), 'Should Deflationists be Dialetheists', Nô̂s 37, 303-324.

[4] Eklund, Matti (2002a), 'Deep Inconsistency', Australasian fournal of Philosophy $80,32 \mathrm{I}-33 \mathrm{I}$.

\footnotetext{
${ }^{\mathrm{I} 8}$ We thank an anonymous referee of the fournal for making this point.
} 
[5] Eklund, Matti (2002b), 'Inconsistent Languages', Philosophy and Phenomenological Research 64, 25I-275.

[6] Priest, Graham (1987), In Contradiction (Dordrecht: Martinus Nijhoff); second (extended) edition, Oxford: Oxford University Press, 2006.

[7] Priest, Graham (1995), Beyond the Limits of Thought (Cambridge: Cambridge University Press); second (extended) edition, Oxford: Oxford University Press, 2002.

[8] Priest, Graham (1998), 'To Be and Not to Be-that is the Answer; Aristotle on the Law of Non-Contradiction', Philosophiegeschichte und Logische Analyse I, 9I-I3O; reprinted as ch. I of Priest (2006).

[9] Priest, Graham (2000), 'Truth and Contradiction', Philosophical 2uarterly 50, I89-195; reprinted as ch. 2 of Priest (2006).

[Io] Priest, Graham (200I), 'Why it's Irrational to Believe in Consistency', pp. 284-93 of B. Brogard and B. Smith (eds.), Rationality and Irrationality: Proceedings of the 23rd International Wittgenstein Symposium, Vienna: öbv\&hpt Verlagsgesellschaft mbh \& Co.; reprinted as ch. 7 of Priest (2006).

[II] Priest, Graham (2006), Doubt Truth to be a Liar, Oxford: Oxford University Press. 
The Australasian fournal of Logic (ISSN I448-5052) disseminates articles that significantly advance the study of logic, in its mathematical, philosophical or computational guises. The scope of the journal includes all areas of logic, both pure and applied to topics in philosophy, mathematics, computation, linguistics and the other sciences.

Articles appearing in the journal have been carefully and critically refereed under the responsibility of members of the Editorial Board. Only papers judged to be both significant and excellent are accepted for publication.

The journal is freely available at the journal website at

$$
\text { http://www.philosophy.unimelb.edu.au/ajl/ }
$$

All issues of the journal are archived electronically at the journal website.

SuBSCRIPTIONS Individuals may subscribe to the journal by sending an email, including a full name, an institutional affiliation and an email address to the managing editor at ajl-editors@unimelb.edu.au Subscribers will receive email abstracts of accepted papers to an address of their choice. For institutional subscription, please email the managing editor at ajl-editors@unimelb.edu.au.

Complete published papers may be downloaded at the journal's website at http: //www.philosophy.unimelb.edu.au/ajl/ The journal currently publishes in pdf format.

Submission The journal accepts submissions of papers electronically. To submit an article for publication, send the $\mathrm{LT}_{\mathrm{E}} \mathrm{X}$ source of a submission to a member of the editorial board. For a current list of the editorial board, consult the website.

The copyright of each article remains with the author or authors of that article. 